\title{
Experimental Study of the Effect of Radially Distorted Inflow on a Contrarotating Fan Stage
}

\author{
Chetan Mistry and A. M. Pradeep \\ Department of Aerospace Engineering, Indian Institute of Technology Bombay, Powai, Mumbai 400 076, India \\ Correspondence should be addressed to A. M. Pradeep; ampradeep@aero.iitb.ac.in
}

Received 31 December 2013; Accepted 27 February 2014; Published 26 March 2014

Academic Editor: J.-C. Han

Copyright (C) 2014 C. Mistry and A. M. Pradeep. This is an open access article distributed under the Creative Commons Attribution License, which permits unrestricted use, distribution, and reproduction in any medium, provided the original work is properly cited.

\begin{abstract}
The paper reports results of a detailed study of hub- and tip-strong radial inflow distortion on the performance of a low speed, high aspect ratio (3.0) contrarotating fan stage. The distortion screen (placed upstream of the first rotor) covers $1 / 3$ of the span of the blade near the hub and the casing for hub-strong and tip-strong inflow distortions, respectively. The performance of the contrarotating fan was investigated under both the radially distorted inflows and compared with the clean inflow conditions under different speed combinations of rotor- 1 and rotor-2. The hub-strong radial distortion reduces the overall performance (pressure rise and efficiency) as well as the operating range by about 2 to $4 \%$ under the different speed combinations. On the other hand, it is interesting to observe that the tip covered radial distortion not only improves the pressure rise, but also increases the overall operating range by about 6 to $8 \%$. There was, however, a 6 to $8 \%$ decrease in efficiency in this case as compared to 12 to $15 \%$ for hubstrong radial inflow distortion. The results reveal the physics of the effects of radial inflow distortion on the overall performance of the contrarotating fan stage.
\end{abstract}

\section{Introduction}

The need for fuel efficient aircraft engines both for civil and military application has over the years motivated researchers to carry out intense research activities to achieve higher efficiency and extend operating range and stability margin of the compressor. For the design of most of these fans and compressors, the flow entering the first stage is usually assumed to be uniform and axisymmetric over essentially the entire face of the inlet blade row. However, it is well known that, due to the engine inlet geometry, aircraft manoeuvring, wind gusts, inlet shock patterns, and other interactions, the compressor will most likely operate with inlet conditions that are different from the assumed uniform inlet flow condition. In a multistage compressor, the boundary layer development towards the later stages will manifest itself in the form of increased blockage and a radial nonuniformity in the total pressure profile. The presence of tip leakage vortex near the casing complicates the flow even further. This radial nonuniformity acts as a radially distorted inflow for the compressor stages that follow. Some of the fuselage mounted engines could also experience a radially distorted inflow due to the ingestion of boundary layer from the fuselage. Thus it becomes necessary for any new design of an axial flow compressor or fan to have in-depth understanding of the response of a compressor/fan to a distorted inflow. The distorted inflow may be circumferential, radial, or a combination of both radial and circumferential distortion. The compressor/fan response to inflow distortions could be different depending upon the nature of the nonuniformities.

There is, however, very limited published literature on the effects of inflow distortion on a contrarotating fan. Roy et al. [1] reported the effect of circumferential inlet distortion with co- and counter-swirl distortion on the performance of a low aspect ratio contrarotating fan. It was observed that the distortion index is the highest for the case of a combination of $90^{\circ}$ total pressure distortion and a $90^{\circ}$ localized counter-swirl. The severity of the combined distortion is more for a contrarotating stage as compared to a single axial fan. A significant outcome of the study is the fact that, in spite of a higher distortion, counter-swirl produces a lower degradation in the performance compared to the coswirl, which has lower distortion intensity. A numerical and experimental study for a complex distortion case was 
attempted by Mileshin et al. [2] for different flight conditions. It was reported that no changes in total pressure ratio are observed at the same rotational speed for a uniform and a nonuniform flow at the inlet. Interestingly, an increase in the total pressure rise and adiabatic efficiency was observed.

Sandercock and Sanger [3], in their studies on a transonic compressor, reported a decrease in the pressure ratio and the stall margin for tip radial distortion. However, only a marginal change in the pressure ratio and stall margin for a hub radial distortion was observed. It was also found that the change in the incidence angle in the distorted and undistorted region changes the blade loading and thereby changes the total pressure ratio of the stage. Moss [4] conducted experiments on the J85-13 compressor with and without wall treatment over the rotor tip in combination with hub and tip radial distortion. About 1-2\% drop in the overall efficiency and about $4 \%$ drop in the stall pressure ratio were observed for the case without wall treatment and with tip radial distortion. In the presence of hub radial distortion, a slight increase in the efficiency and stall margin was observed. Drop in efficiency was also observed in the presence of wall treatment and tip as well as hub radial distortion. It was finally concluded that the engine was hub critical and therefore tip treatment did not have a beneficial effect on the stall margin. Schmidt and Ruggeri [5] designed a transonic fan stage with the objective of reduced tip loading to improve the stable operating range and the tolerance to tip radial distortion. Three different magnitudes of tip and hub radial distortions under different speed combinations were tested. A significant reduction in the stall margin with tip radial distortion was observed. For the hub radial distortion, a sharp decrease in the stall margin and the pressure ratio at the design speed was observed. There was no corresponding change in the efficiency. At 70\% design speed, there was no change in the stall margin or other performance parameters. Sanger [6] reported the effect of tip radial distortion with $90^{\circ}$ circumferential distortion on the performance of three transonic compressors, each having different outlet-to-inlet ratios of meridional velocity (vector sum of axial and radial velocity components) across the rotor. The rotor with lower meridional velocity (less than 0.9 at tip) demonstrated the least degradation in the performance from a tip radial distortion, which is similar to an undistorted flow. The rotor with high-meridional velocity ratio (greater than 1.0 at tip) sustained a larger loss in performance due to tip radial distortion. This is due to the tip region with low-meridional velocity ratio showing stronger recovery to circumferential distortion than the high-meridional velocity ratio.

Many of the recent experimental and numerical studies have focused on studying the effect of different inlet total pressure distortion on the overall performance of a compressor/fan $[7,8]$ to achieve improvement in the performance and distortion insensitive rotors. Spakovszky et al. [7] attempted to stabilize rotating stall and studied stall inception pattern in a single-stage transonic compressor with radial inlet distortion using active feedback control. Chima [8] has computationally studied the performance of NASA stage 35 using a 3D unsteady code and found that the performance agreed well with the experimental results with radial distortion and shows reduction in the stable flow range of the compressor. Yang and $\mathrm{Gu}$ [9] have conducted experimental and computational investigations to evaluate the effects of radially distorted incident flow on the performance of an axial flow fan with three kinds of forwarded-skewed blades. The results reveal the beneficial effect of forward-skewed blade on the performance. However, the fan performance and its unsteady aerodynamic characteristics are quite significantly affected by the radially distorted incident flow.

Though the important aspect of radially distorted inflow on the performance of axial flow compressor/fan has been reported for single-stage and low aspect ratio blades, very few studies have focused on the effects of radial inflow distortion on the performance of a contrarotating axial fan.

The present paper discusses the detailed experimental study carried out to understand the effect of radial distortion on a high aspect ratio contrarotating axial fan stage. Radial inflow distortion was generated by means of screens located upstream of the first rotor. Both hub-strong and tip-strong radial inflow distortions were introduced at the inlet. The response of the contrarotating fan to each inflow case was studied under different rotational speed combinations of the two rotors. The effects of these two types of radial inflow distortions on the performance of the stage and the associated flow physics are explored through radial traverse measurements across the stage.

\section{Experimental Setup and Instrumentation}

The test setup for the present study is a low speed contrarotating test facility at the Indian Institute of Technology Bombay and is shown in Figure 1. Two AC induction motors of $15 \mathrm{~kW}$ with separate variable frequency drives (VFD) are used to drive the rotors at different speed combinations. The VFD also has a provision to measure and display the power consumed by the motors. To avoid flow blockage in front of the rotors, the motor drive is connected to the rotor shaft with a belt and pulley arrangement as shown in Figure 1. Air enters the test section through a calibrated bell mouth. A conical throttle valve controls the mass flow rate at the exit. Rotor1 has 19 blades and rotor-2 has 17 blades, each with an aspect ratio of 3 and a chord of $45 \mathrm{~mm}$. Details of the rotor blades and of the experimental facility are described in detail in Mistry and Pradeep [10].

The total pressure inflow distortion is simulated by means of a (tip or hub) radial distortion screen placed as shown in Figure 1. The distortion screen comprised a stainless steel mesh with a wire diameter of $1 \mathrm{~mm}$ and 4 mesh counts per inch resulting in a porosity of 0.70 to achieve the desired distortion intensity. The distortion screen sectors were placed $580 \mathrm{~mm}$ (1.42 times the casing diameter) upstream from the leading edge of rotor-1.

Figure 2 shows the distortion configuration along with direction of rotation of the two rotors (when viewed in the direction of the flow). The distortion screen covers $1 / 3$ of the span of the blade. In order to carry out a detailed study of the flow physics under the distorted inflow conditions, two seven-hole probes (from M/s Aeroprobe Inc., US) and a 


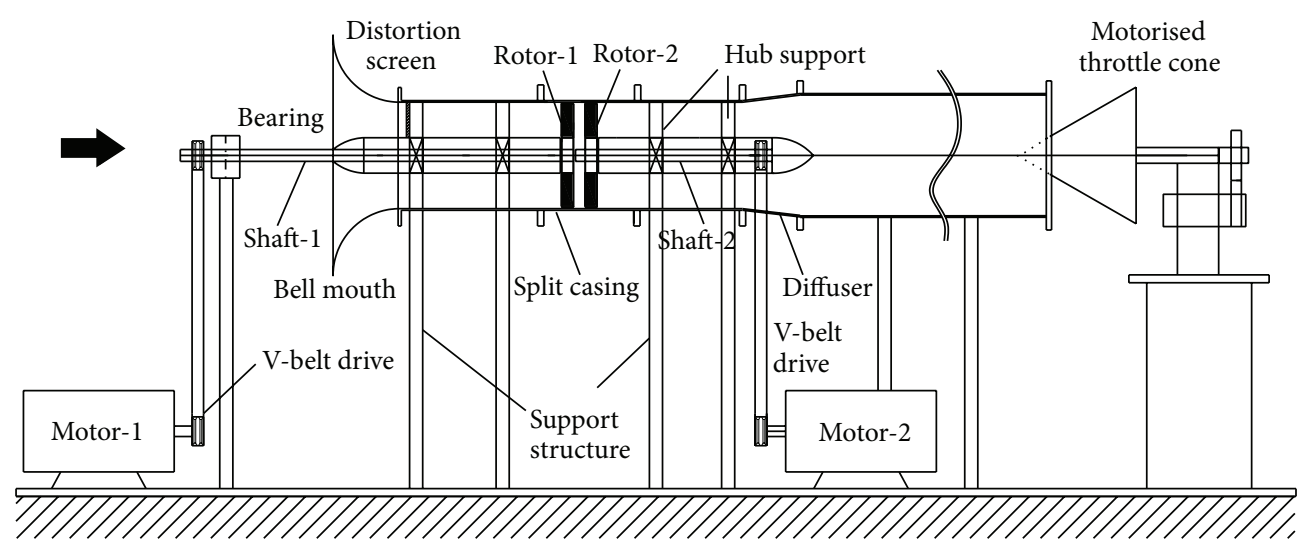

FIGURE 1: Experimental setup with distortion screen.

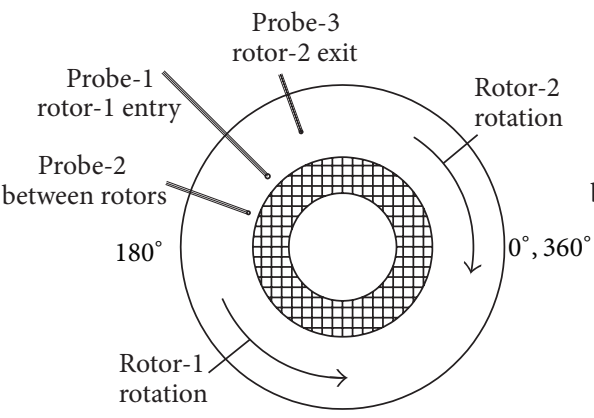

(A) Hub-strong radial distorted screen

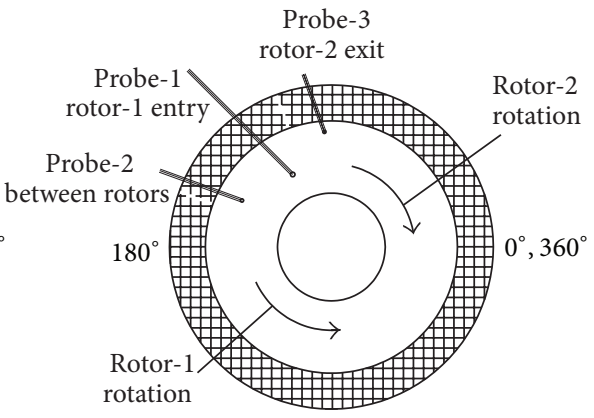

(B) Tip-strong radial distorted screen

(a)

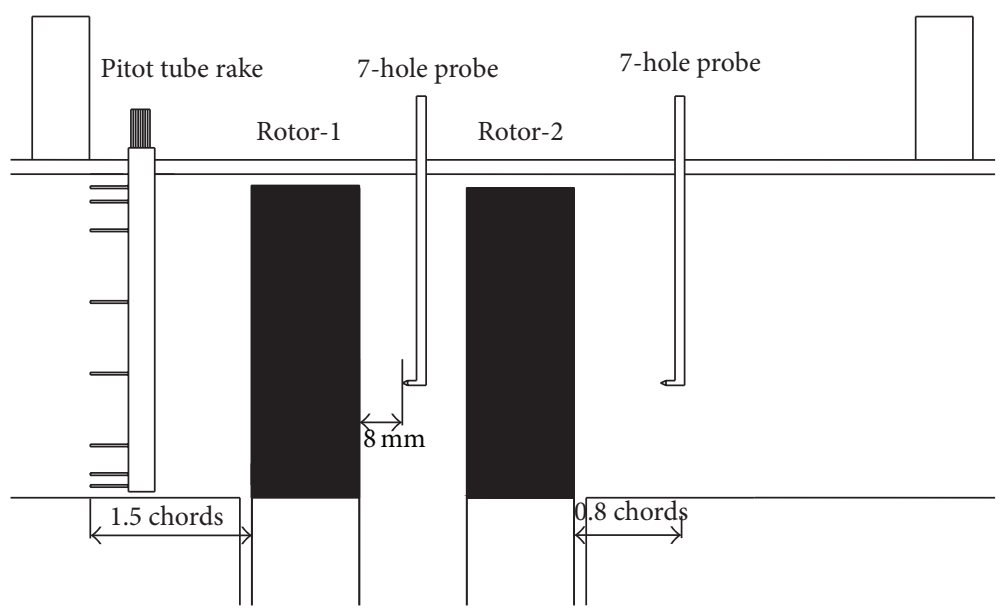

(b)

FIGURE 2: Schematic layout of the (a) distortion configurations and (b) probe locations.

pitot rake were used as shown in Figure 2. A pitot probe rake comprising of 8 pitot tubes, each of $1 \mathrm{~mm}$ diameter, was used for measuring the total pressure at the inlet of rotor-1. Two such pitot tube rakes were placed at a distance of 1.5 chords and diagonally opposite to each other, to measure the total pressure at the inlet. A miniature seven-hole probe of $1.6 \mathrm{~mm}$ diameter was placed between the rotors to investigate the flow physics in between the rotors and is placed $8 \mathrm{~mm}$ downstream of the rotor-1 trailing edge. The second seven-hole probe is placed 0.8 chords downstream of the rotor- 2 trailing edge. Both the seven-hole probes and the pitot tube rakes were connected to pressure scanners (from M/s Scanivalve Corp., US) for recording the pressures. The logged data is converted to total pressure, static pressure, velocity components, and the flow angles using AeroAcquire ${ }^{\hat{s}}$ software. The measured accuracies of these instruments were $\pm 1 \%$ of full scale 
(full scale $=5040 \mathrm{~Pa}$ ). For probe traverse, a precision traverse with a pitch of $0.5 \mathrm{~mm}$ was used.

In order to study the flow physics at the inlet of rotor1 , the exit of rotor-1, and exit of rotor- 2 under the design and the peak pressure mass flow rates for different speed combinations of the rotors, three seven-hole probes were placed at locations indicated in Figure 2(a). These probes were traversed using an automated traverse mechanism to record larger number of readings near the tip and the hub regions. All the three seven-hole probes were connected to pressure scanners (from M/s Scanivalve Corp., US) for recording the pressures. The seven-hole probe was placed 1.2 chords upstream of the leading edge of rotor-1. This factory calibrated probe has a flow speed measurement range of Mach 0.1 to 0.73 with direction sensitivity of $\pm 75^{\circ}$. A miniature seven-hole probe of $1.6 \mathrm{~mm}$ diameter was placed between the rotors to study the detailed flow features between the rotors and was placed $8 \mathrm{~mm}$ downstream of the rotor-1 trailing edge. A third seven-hole probe was placed 0.8 chords downstream of the rotor- 2 trailing edge. The probe measured total pressure, static pressure, velocity components, and flow angles through the postprocessing software.

\section{Results and Discussion}

The results of this investigation are presented in two main sections: hub-strong radially distorted inlet flow and tipstrong radially distorted inflow. The study focuses on the effect of different speed combinations of the rotors on the performance of the contrarotating stage. This particular axial spacing was chosen based on the observations reported in Mistry and Pradeep [11]. The speed of rotor-1 was maintained constant at a design speed of $2400 \mathrm{rpm}$ (referred to as $N_{d}$ ) and the speed of rotor- 2 was varied as $2200 \mathrm{rpm}, 2400 \mathrm{rpm}$, and $2600 \mathrm{rpm}$, respectively, denoted as $0.91 N_{d}, N_{d}$, and $1.08 N_{d}$.

3.1. Hub-Strong Radially Distorted Inflow Condition. The performance of the contrarotating fan under clean and hubstrong radial inflow distortion for the three different speed combinations is shown in Figure 3. The pressure coefficient of the contrarotating fan stage under clean inflow condition shows the built-up pressure with the reduction in the mass flow rate. A peak pressure as seen for conventional axial flow compressor/fan is subsequently achieved. With further reduction in the mass flow rate, the pressure begins to drop. However, the drop in the pressure is very gradual. This trend is observed for all the three speed combinations of $N_{d^{-}}$ $1.08 N_{d}, N_{d}-N_{d}$, and $N_{d}-0.91 N_{d}$. The pressure measurement at the exit of rotor-1 allows evaluating the pressure rise across individual rotors. The presence of two possible stall regimes, partial stall and full stall, in clean flow and under circumferential inflow distortion has already been reported in Mistry and Pradeep [10]. A similar trend is observed under the hub-strong radial inflow distortion as well. The speed combination of $N_{d}-1.08 N_{d}$, which corresponds to a higher rotational speed of rotor-2, appears to be advantageous in terms of higher pressure rise. The higher rotational speed of rotor- 2 shifts the peak pressure mass flow rate towards the

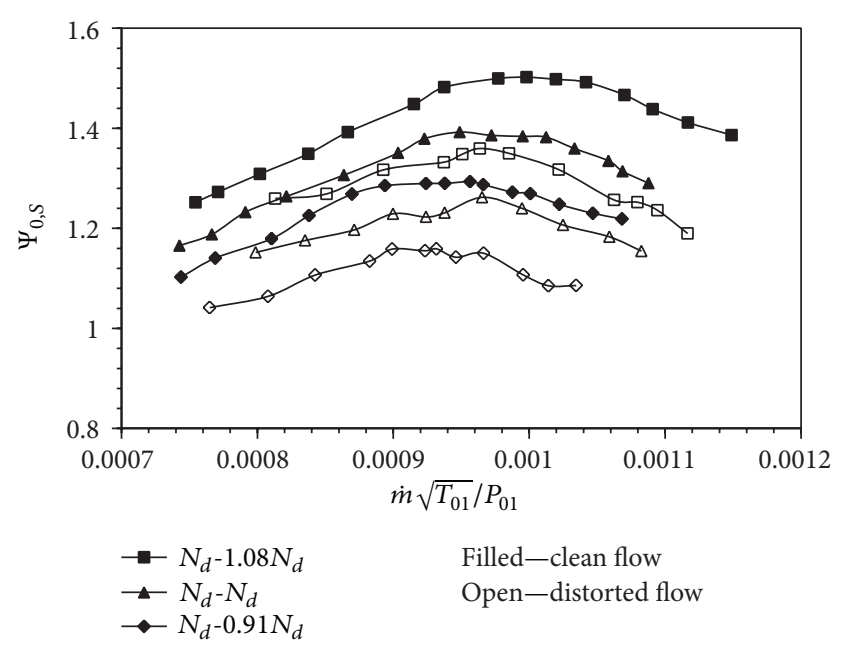

Figure 3: Performance characteristics under clean and hub-strong radial inflow distortion.

higher mass flow rate which is closer to the design mass flow rate. Similarly, lower rotational speed of rotor-2 results in drop in the pressure rise and the peak pressure mass flow rate is lower than that observed for the design speed combination.

The pressure rise margin and the stall margin are, respectively, 5 to $10 \%$ and 2 to $4 \%$ lower for the stage with inflow distortion. These were calculated using the following expressions:

Pressure rise margin

$$
\begin{gathered}
=\frac{\left(P_{0, \text { peak pressure, Clean }}-P_{0, \text { peak pressure, Distorted }}\right)}{P_{0, \text { peak pressure, Clean }}} \\
\text { Stall margin }=\frac{\left(\dot{m}_{\text {peak pressure, Clean }}-\dot{m}_{\text {peak pressure, Distorted }}\right)}{\dot{m}_{\text {peak pressure, Clean }}} .
\end{gathered}
$$

The stage performance characteristics show similar trends with distorted inflow even for the various speed combinations. The performance of the stage under distorted inflow too is observed to be better when rotor- 2 operates at a higher rotational speed. Therefore, for both clean and distorted inflow conditions, the speed of the second rotor plays a significant role in the overall stage performance. The overall efficiency of the stage under clean and distorted inflow conditions is shown in Figure 4. There is a substantial drop (peak efficiency drops in the range 12 to $15 \%$ ) in the efficiencies in the presence of hub-strong radial inflow distortion. The physics of the flow under the distorted inflows will be explored in the succeeding sections.

\subsection{Flow Behaviour with Hub-Strong Radial Inflow Distortion.} Based on the performance characteristics of the stage and that of the individual rotors, it was decided to carry out detailed flow-field measurements at the inlet of rotor-1, exit of rotor1 , and exit of rotor- 2 to understand the effect of hub-strong inflow distortion. These separate measurements were carried 


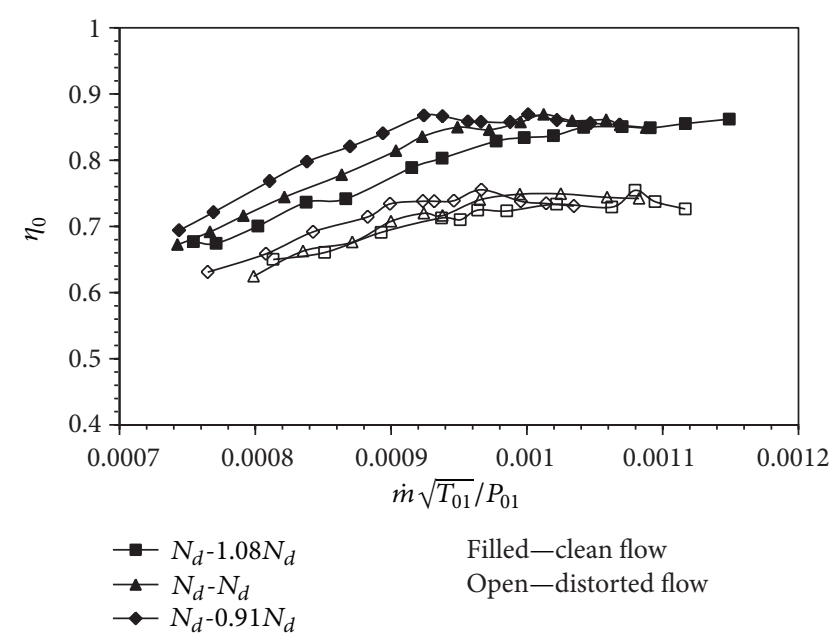

FIgURE 4: Variation of overall efficiency under clean and hub covered distorted flow.

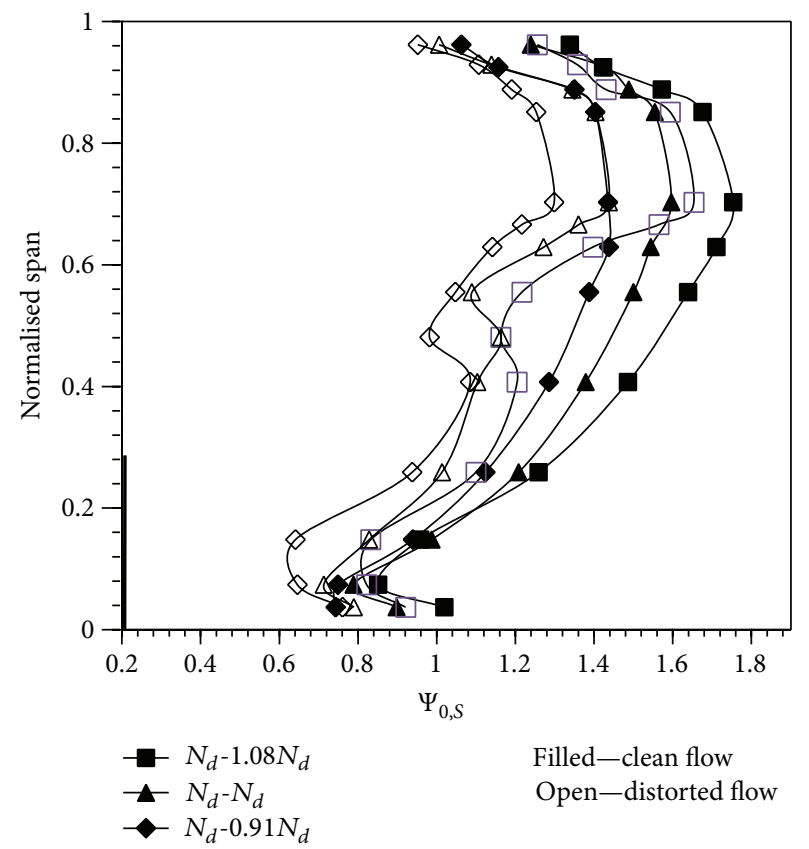

FIGURE 5: Spanwise variation of total pressure rise coefficient: design mass flow rate.

out to explore the extent of distortion on which very little has as yet been reported in literature so far as a contrarotating fan stage is concerned. These measurements were carried out at the design and the peak pressure mass flow rates.

Figure 5 shows the stage total pressure rise coefficient along the span of the rotor under both clean and hub-strong radial distortion for the three different speed combinations. For the clean inflow case, there is a rise in the total pressure as can be seen all the way from the hub to the tip for the design mass flow rate. Higher aerodynamic loading can be observed nearly about $60 \%$ span to $90 \%$ span. This is in line with the design of the rotors with higher loading near the tip region [11]. The magnitude of the pressure coefficient near the tip region decreases. This reduction in the total pressure is due to the boundary layer and end wall effects. Under the peak pressure mass flow rate, the total pressure coefficient is observed to be higher, nearly about and above $60 \%$ span, which shows the improvement in performance with reduction in the mass flow rate.

As seen from Figure 5, at the design mass flow rate, in the vicinity of $45 \%$ span from the hub, the effects of hub-strong radial distortion are visible. The performance of the stage is found to be improved with the increase of the rotational speed of rotor-2, which is similar to what is observed for the clean inflow condition [11]. For the distorted inflow condition, up to $45 \%$ span is found to be significantly affected showing a reduction of the pressure coefficient in that region for all the speed combinations. Under distorted inflow condition, the pressure rise coefficient in the region above $60 \%$ span is observed to be higher than the rest of the span. However, the pressure rise coefficient falls short of the magnitudes observed under clean inflow condition. Near the tip region above $80 \%$ span, for higher rotational speed of rotor-2, the pressure rise coefficient has nearly the same magnitude as that observed for cleaninflow. In general, it is observed that the effects of the hub-strong radial inflow distortion are not restricted to the $30 \%$ of the span, but over a larger part of the span.

To understand the propagation of the distorted inflow at the exit of rotor-1, the axial velocity normalized with the blade tip speed is used as seen in Figure 6(a); under both the inflow conditions, the variation in the axial velocity ratio along the span is observed to be negligible for the different speed combinations. These effects are also seen in the absolute flow angle at the exit of rotor-1 as shown in Figure 6(b). As seen from the figure, the flow angle changes along the span of the blade by about 3 to 4 degrees along the span with distortion. This can also be compared with the axial velocity, which is higher than that of the clean flow as shown in Figure 6(a). The differences in the flow angles from the hub region to about $40 \%$ span for the clean and the hub-strong radial distortion are marginal. The flow angles under the design mass flow rate condition show an increase in its magnitude of the order of 3 to 5 degrees from $40 \%$ to $80 \%$ of the span. The change in the flow angle is marginal compared to the clean inflow case in this region. Subsequently, the flow incidence to rotor2 (slightly above $40 \%$ span) will change and this will, in turn, change the flow pattern and flow behaviour on rotor-2. For the different speed combinations, the flow parameters at the exit of rotor-1 for both design and the peak pressure mass flow rate show negligible variations in their magnitudes. These changes in the parameters are likely to minimally affect the performance of rotor-2.

Figure 7 shows the variation in the axial velocity ratio along the span at the exit of rotor-2. The axial velocity ratio at the exit of rotor- 2 shows a significant reduction in its magnitude near the hub region as compared to the exit of rotor-1. This indicates the residual effect of the hubstrong radial distortion in the hub region of rotor-2. This is compensated by an increase in the mass flow/axial velocity away from the hub. There is, therefore, a migration of flow from the hub region towards the higher span locations. Near 


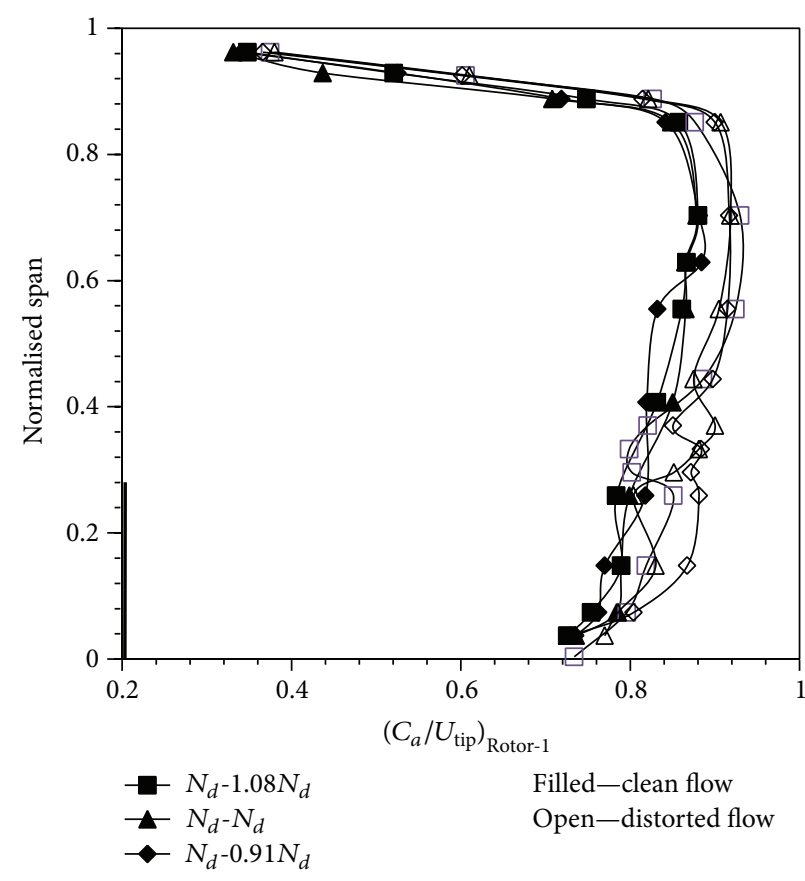

(a)

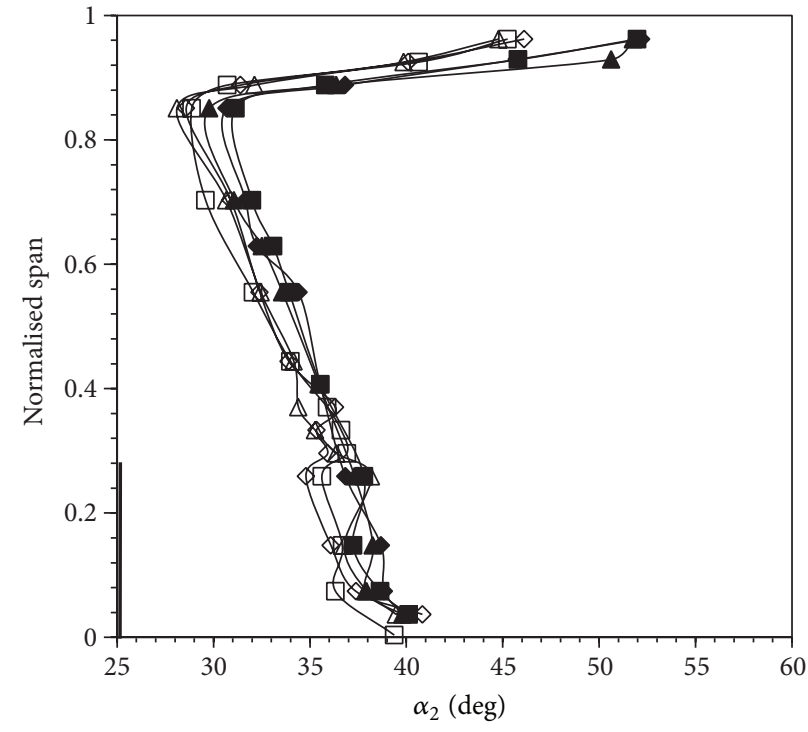

$\multimap N_{d}-1.08 N_{d}$
$\longleftarrow N_{d}-N_{d}$
$\multimap-N_{d}-0.91 N_{d}$

Filled-clean flow Open-distorted flow

FIGURE 6: Spanwise variation of (a) axial velocity ratio and (b) flow angle at exit of rotor-1.

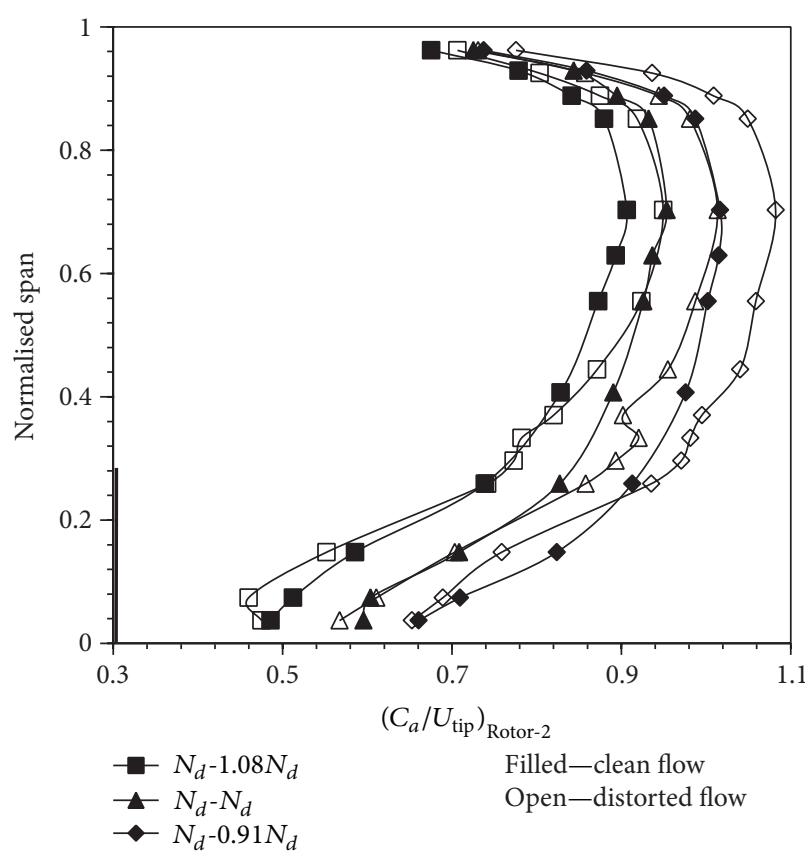

(a) Design mass flow rate

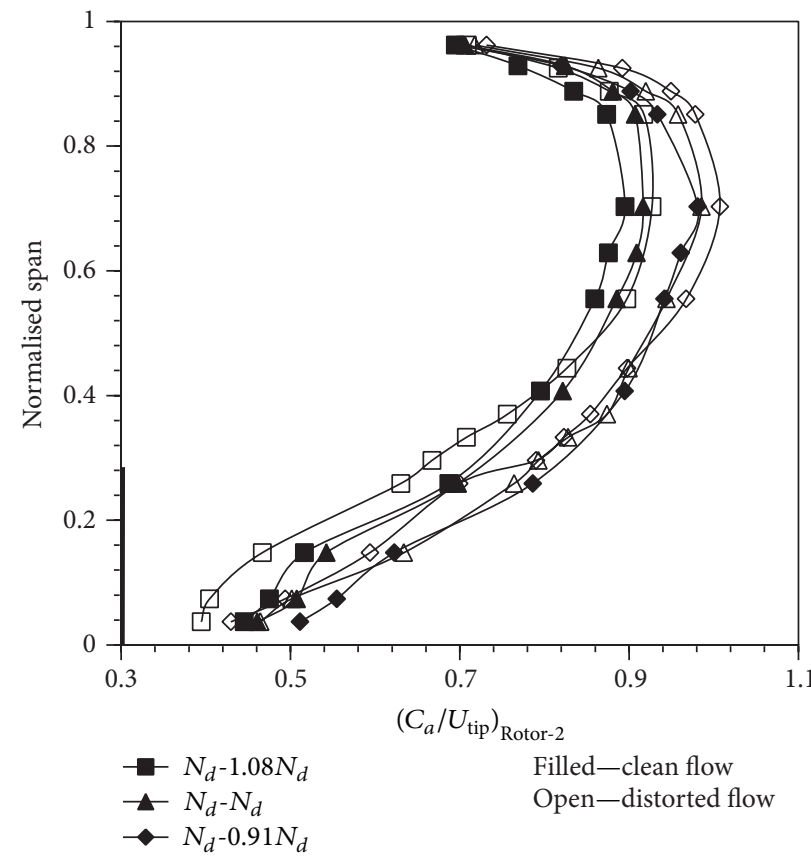

(b) Peak pressure mass flow rate

FIgURE 7: Spanwise variation of axial velocity ratio at the exit of rotor-2.

the hub, there is a slight reduction in the axial velocity ratio as compared to the design mass flow rate. As mentioned earlier, the change in the flow angle at the inlet of rotor- 1 changes the flow distribution at the inlet of rotor-2. It is interesting to observe that, with the increasing speed of rotor-2, the axial velocity ratio is reduced for both the mass flow rates. This indicates that the exit flow from rotor-2 may not necessarily be axial as in the case of a clean inflow. This can also be observed in terms of the absolute flow angle distribution at the exit of rotor-2 shown in Figures 8(a) and 8(b). 


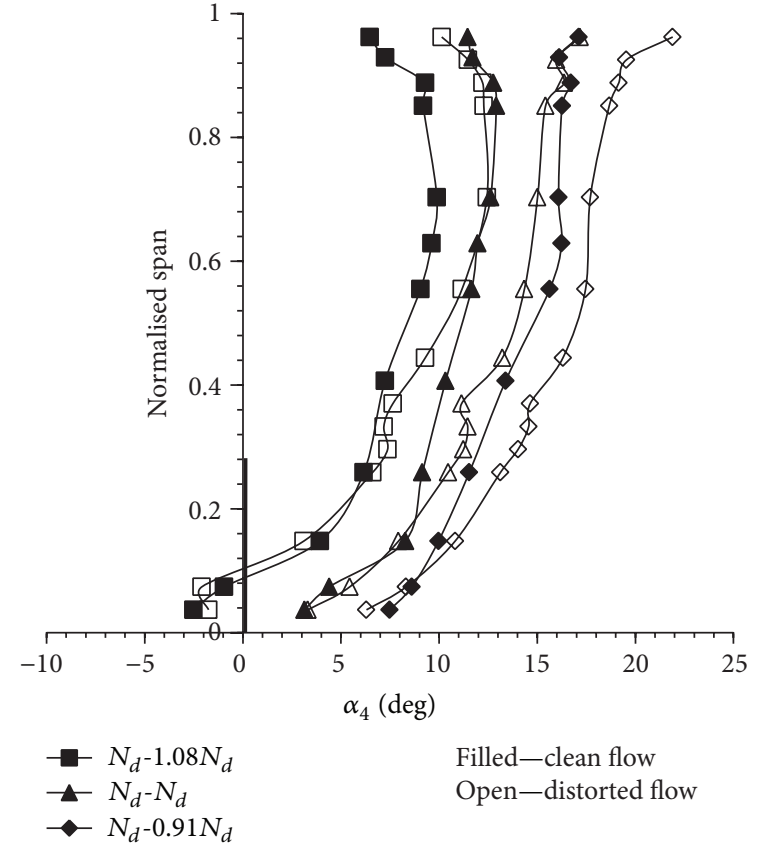

(a) Design mass flow rate

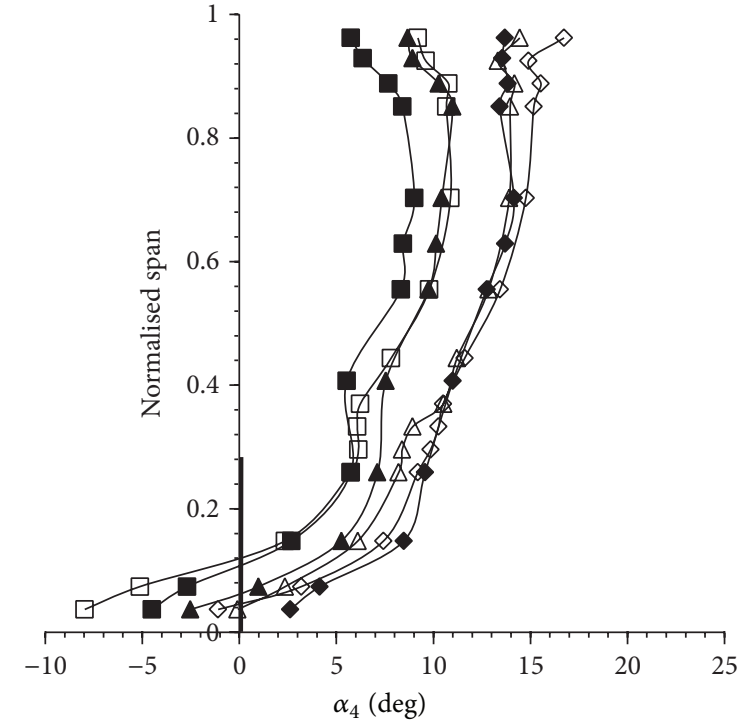

Filled-clean flow Open-distorted flow

(b) Peak pressure mass flow rate

The differences in the flow angles for the two mass flow rates are as shown in Figures 8(a) and 8(b). The flow angle distribution is similar to the clean inflow condition up to about $40 \%$ span for both the design and peak pressure mass flow rates. A rotational higher speed of rotor-2 results in a lower magnitude of the whirl velocity towards the hub region. This is an indication of the reduction of the threedimensionality of the flow at the exit of rotor-2. The lower magnitude of the flow angles also indicates a good diffusion in the blade passage. Under the peak pressure mass flow condition, the effect of inflow distortion seems amplified due to the lower mass flow rates. The flow angle from about $40 \%$ span to the tip region shows an increase in its magnitude of the order of 3 to 5 degrees for both the design and the peak pressure mass flow rates, but lower in magnitude for higher rotational speed of rotor-2. Thus, higher rotational speeds of rotor-2 result in an improvement in the performance of the stage as discussed in the context of the performance map earlier on.

Figure 9 shows the total pressure coefficient distribution along the span at the inlet of rotor-1, the exit of rotor-1, and the exit of rotor- 2 under the design speed combinations for the design mass flow rates. The effect of hub-strong inflow distortion can be seen as in the figure at the inlet of rotor1 , where the total pressure coefficient shows a significant gradient in its magnitude up to about $45 \%$ span of the blade from the hub. The effect of distortion gets transferred through rotor- 1 and has a similar trend of reduction in its magnitude at nearly the same extent of $45 \%$ span at the exit of rotor- 1 . However, at the exit of rotor-2, the total pressure coefficient shows signs of recovery above the distorted sector region (between 0.45 and 1.0, normalized span).

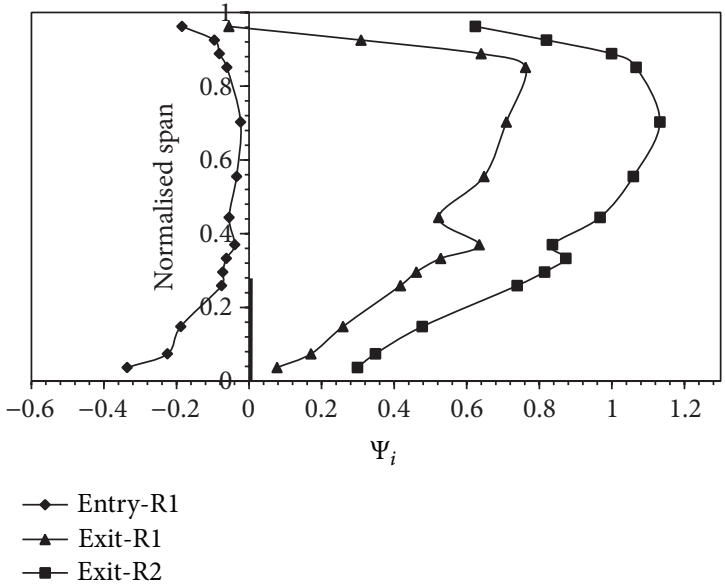

FIGURE 9: Spanwise total pressure coefficient along the stage at design speed combination.

For the hub-strong radial inflow distortion, the distorted region near the hub results in a lower magnitude of flow parameters like velocity components, flow angles, and the total pressure at the inlet of rotor-1. As the flow with these reduced flow parameters enters rotor-1, the rotor facing the distorted region works under off-design condition while the undistorted region works under the design condition. The high aspect ratio blade permits the flow parameters coming out from the distorted region to adjust themselves along the span. This leads to a migration of flow from the undistorted flow region towards distorted region. The blades of the present contrarotating fan were designed for 


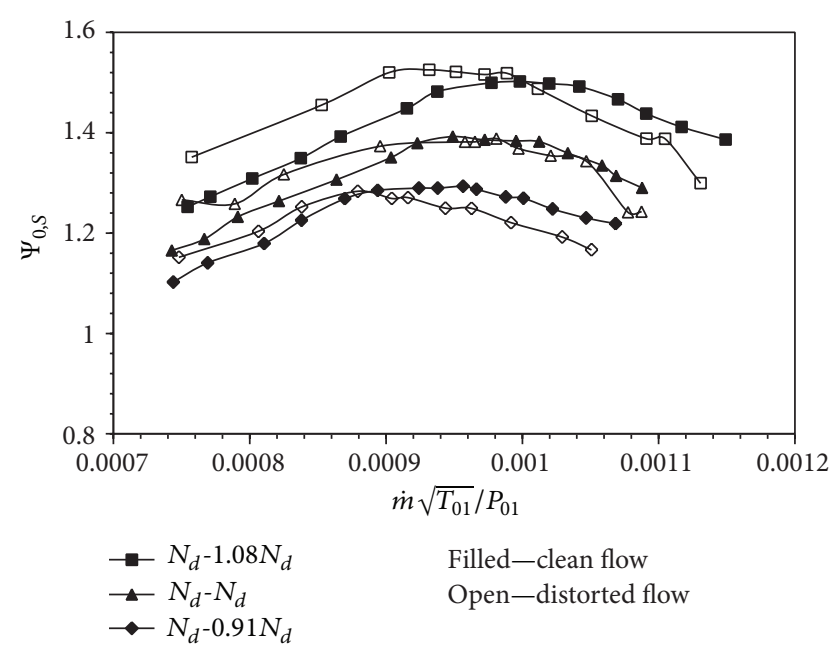

Figure 10: Performance characteristic under clean and tip-strong radial inflow distortion.

higher aerodynamic loading near the tip region and lower aerodynamic loading near the hub. The presence of hub covered radial distortion further lowers the aerodynamic loading in the hub region. This therefore results in a poor overall performance of the stage under hub-strong radial inflow distortion as compared with the clean inflow case.

3.3. Tip-Strong Radial Inflow Distortion. After studying the effect of hub-strong radial distortion on the performance of the contrarotating fan stage, it was decided to carry out a similar study under tip-strong radially distorted inflow. The distortion screen frame for this case was selected as $1 / 3$ of the total span of the blade from the casing and had a porosity of 0.7 . The speed of rotor- 1 was maintained constant at a design speed $\left(N_{d}\right)$ and the speed of rotor- 2 was varied as $0.91 N_{d}, N_{d}$, and $1.08 N_{d}$.

Figure 10 shows the effect of tip-strong radial distortion on the pressure rise across the contrarotating fan stage. The pressure rise across the stage is significantly affected due to tip-strong distorted flow as seen from the figure. It is interesting to note that, for the tip-strong distortion, the performance of the stage improves in terms of pressure rise and the stall margin. As compared to both the clean inflow and the hub-strong inflow distortion, a flatter operating range is observed. The partial stall is indicated by open circle and the full stall region is indicated towards the low mass flow rate for tip-strong radial distortion condition [10]. The stage performance characteristics are similar in trend for the various speed combinations. For higher rotational speed of rotor-2, the pressure rise across the stage, as expected, is better under clean inflow as well as tip-strong radially distorted inflow. The performance of the contrarotating stage shows reduction in performance at higher mass flows under all the speed combinations. However, with reduction in the mass flow, this trend reverses and improved performance is observed.

The overall efficiency of the stage under clean and distorted inflow conditions is shown in Figure 11. Tip-strong

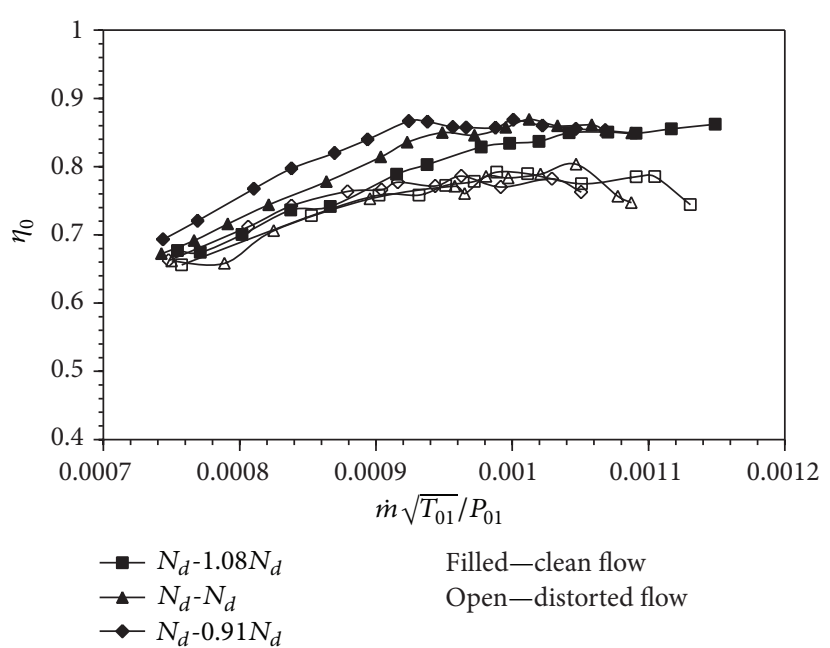

FIGURE 11: Variation of overall efficiency under clean and tip-strong radial inflow distortion.

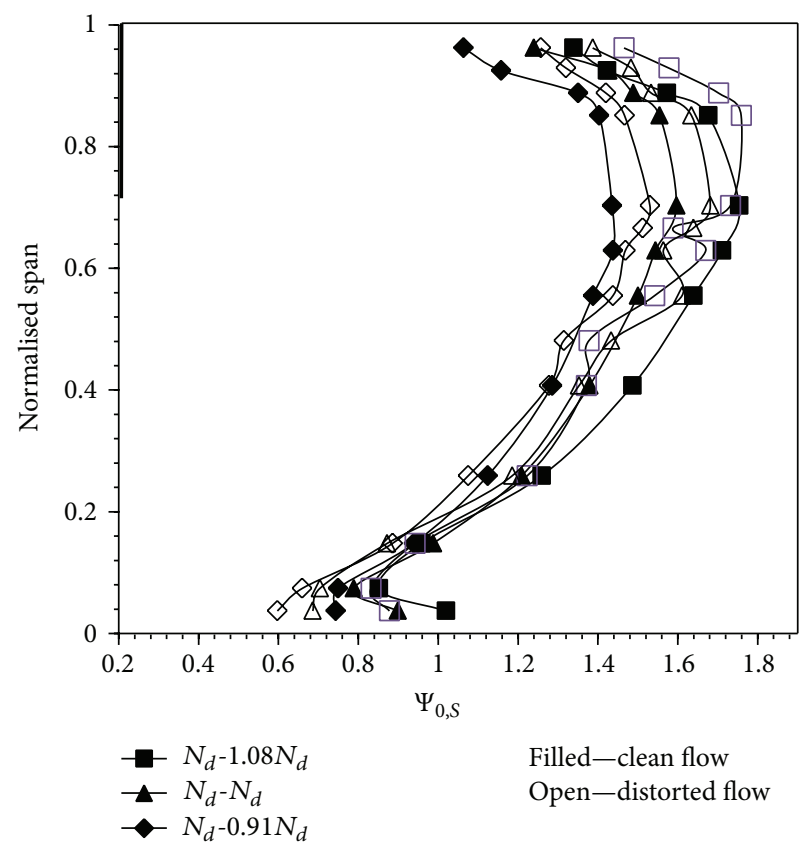

FIGURE 12: Spanwise variation of total pressure rise coefficient: design mass flow rate.

distortion results in a stall margin improvement by about 6 to $8 \%$ compared to the clean flow condition. This is an indication of the advantage of having higher blade loading in the tip region without compromising the operating range significantly. However, a significant reduction of the order of about 6 to $8 \%$ in the peak overall efficiency as compared to 12 to $15 \%$ drop in peak efficiency is observed for the hub-strong distorted inflow (Figure 4).

3.4. Flow Behaviour with Tip-Strong Radial Inflow Distortion. Similar to the hub-strong radial inflow distortion case, detailed flow-field measurements under the tip-strong inflow 


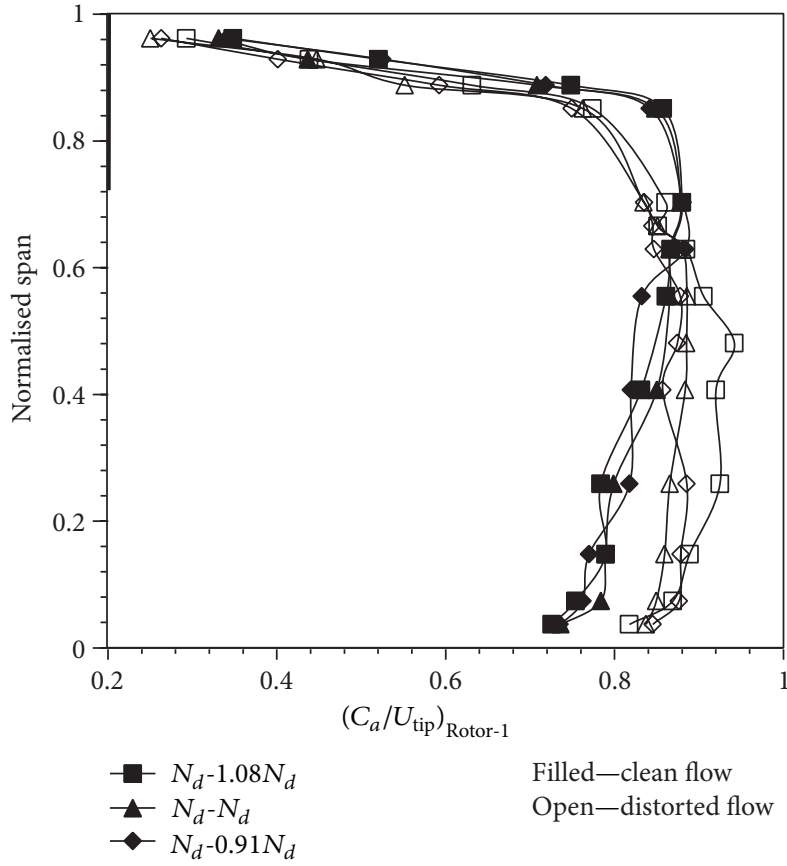

(a)

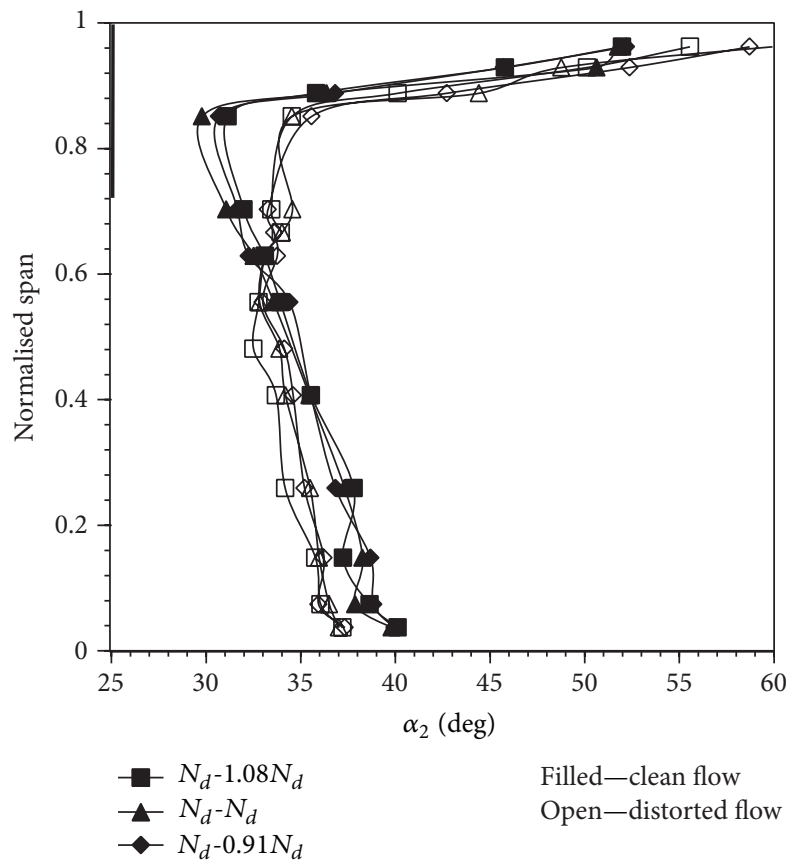

(b)

FIGURE 13: Spanwise variation of (a) axial velocity ratio and (b) flow angle at exit of rotor-1.

distortion at the inlet of rotor-1, exit of rotor-1, and exit of rotor-2 are carried out to understand the effect of tip-strong inflow distortion and its spread throughout the annulus for different rotor speed combination at the design and peak pressure mass flow rate.

Figure 12 shows the total stage pressure rise coefficient along the span of the rotor at the design mass flow rate. As seen from the figure, under the design mass flow rate with both clean and tip-covered distorted inflow, higher loading is observed from nearly about $60 \%$ to the tip. It is interesting to observe that the total pressure rise coefficient with distorted inflow has a higher magnitude compared to the clean inflow. As compared to the hub-strong radial distortion, the peak pressure values above $60 \%$ blade span are significantly higher. This shows an overall improvement in the performance under tip-strong radial inflow compared to both the clean and the hub-strong distorted inflow condition.

The presence of blockage reduces the velocity of flow as it passes through it. The axial velocity is a major parameter, which gets affected by this blockage in the flow facing direction. The presence of the distorted screen reduces the axial velocity in the tip region (Figure 13(a)). This ratio then increases in magnitude towards the midspan region and also towards the hub region compared to both clean flow and hubstrong radially distorted inflow condition. It is interesting to observe here that the axial velocity shows improvement in magnitude at nearly about $60 \%$ span. The blade actually faces the distortion effect above this span height. The distorted flow entering rotor-1 diverts the flow towards the hub region because of change in the flow angles both at the inlet and the exit of rotor-1. Higher rotational speed of rotor-2 increases the magnitude of the axial velocity ratio. This phenomenon can be better explained through the flow angle distribution. For the peak pressure mass flow rate, a similar tendency was observed. The spanwise migration of the flow from the distorted to the undistorted regions was also observed in the case of hub-strong inflow distortion.

The presence of the tip-strong distortion near the casing changes the flow incident on rotor-1 and thereby changes the flow pattern as shown earlier in Figure 13. This change of the incidence angle alters the flow distribution along the entire blade span. The flow angle is reduced by about 5 degrees near the distorted flow region and between 2 and 4 degrees higher along the span for the undistorted region compared to the clean inflow condition under the design mass flow rate (shown in Figure 13(b)). The change in the flow angle along the span indicates the redistribution of the flow at the exit of rotor- 1 along the span. A higher rotational speed of rotor- 2 results in the change in the flow angle in the undistorted region, which has a significant effect on the overall performance of the contrarotating fan.

Figure 14 shows the axial velocity variation at the exit of rotor-2. Variations in the magnitude for a particular speed combination between about $55 \%$ and $90 \%$ span compared to the clean flow condition are observed. Therefore, the increase in the magnitude of the axial velocity at the exit of rotor2 indicates the redistribution of flow in that region. As a result of this there is an improvement in the pressure rise and stall margin of rotor- 2 as explained earlier in the context of Figure 12. For the peak pressure mass flow rate, lower 


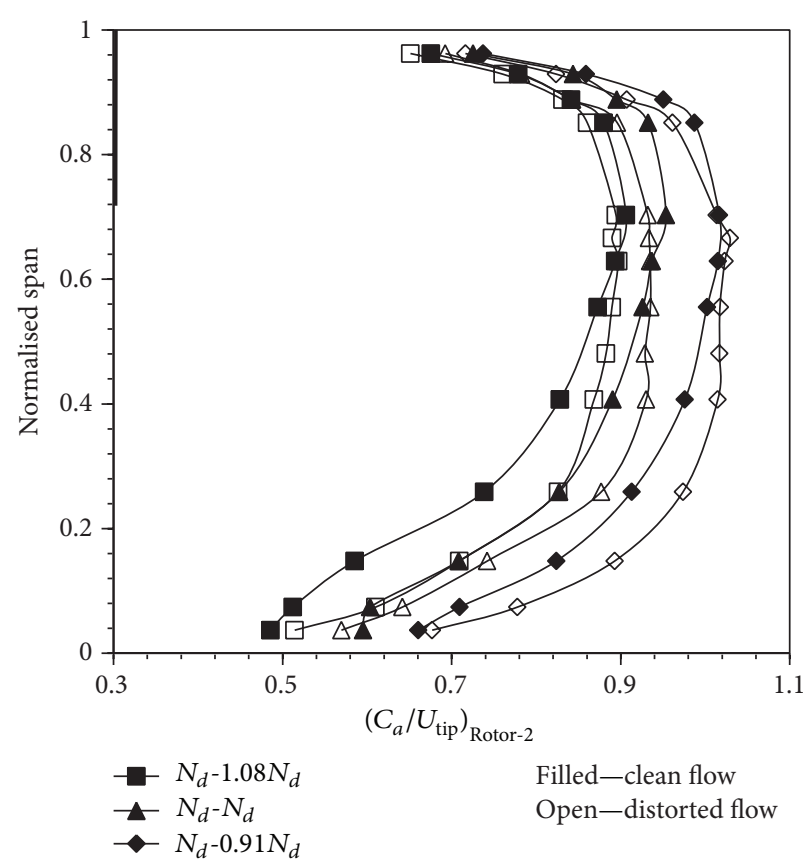

(a) Design mass flow rate

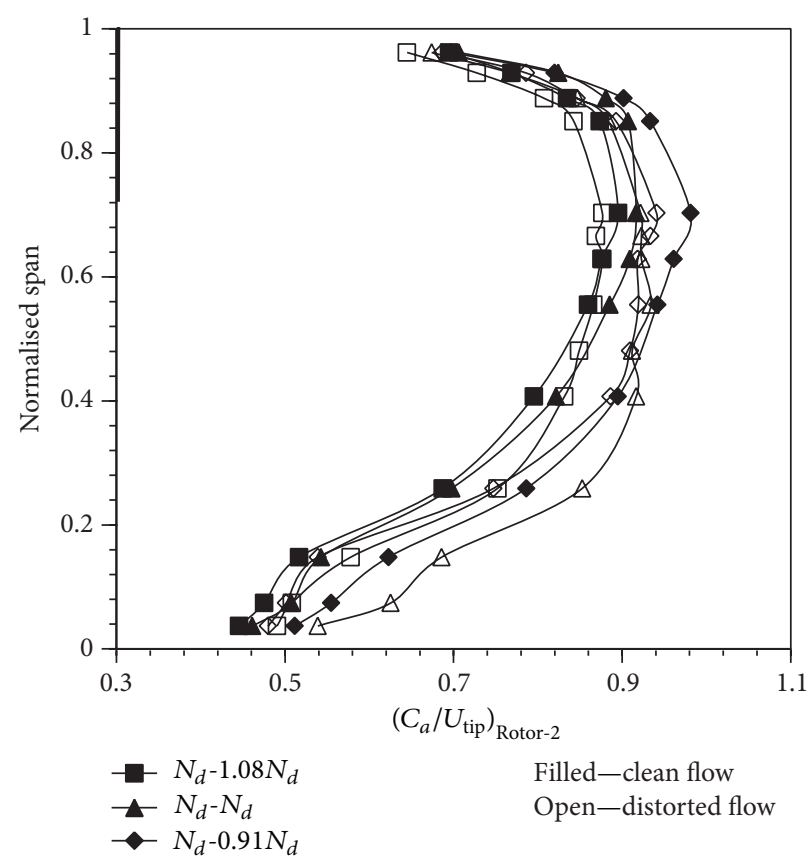

(b) Peak pressure mass flow rate

FIGURE 14: Spanwise variation of axial velocity ratio at the exit of rotor-2.

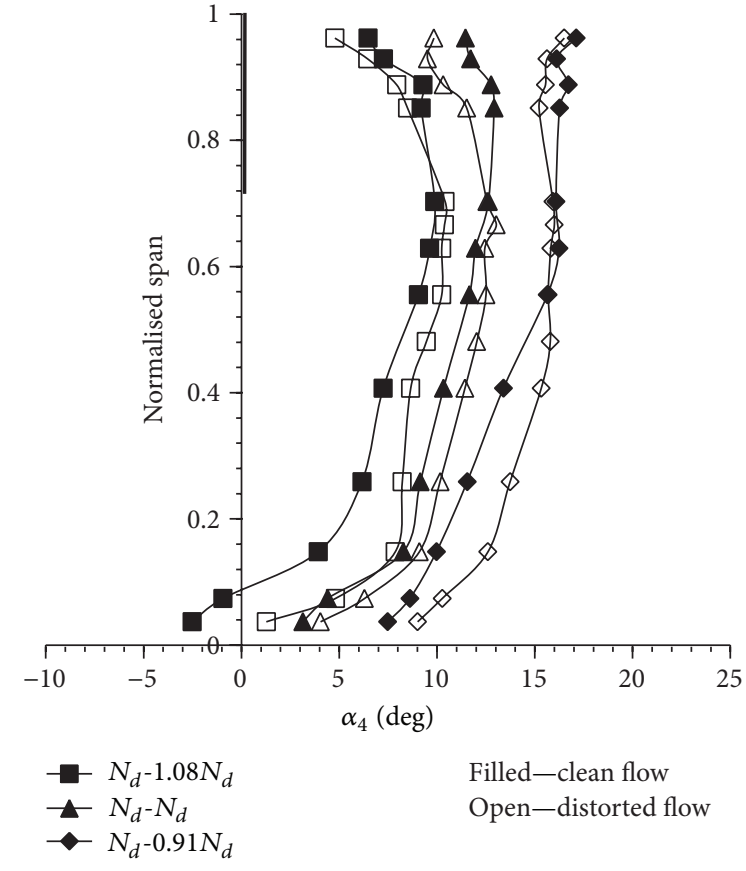

(a) Design mass flow rate

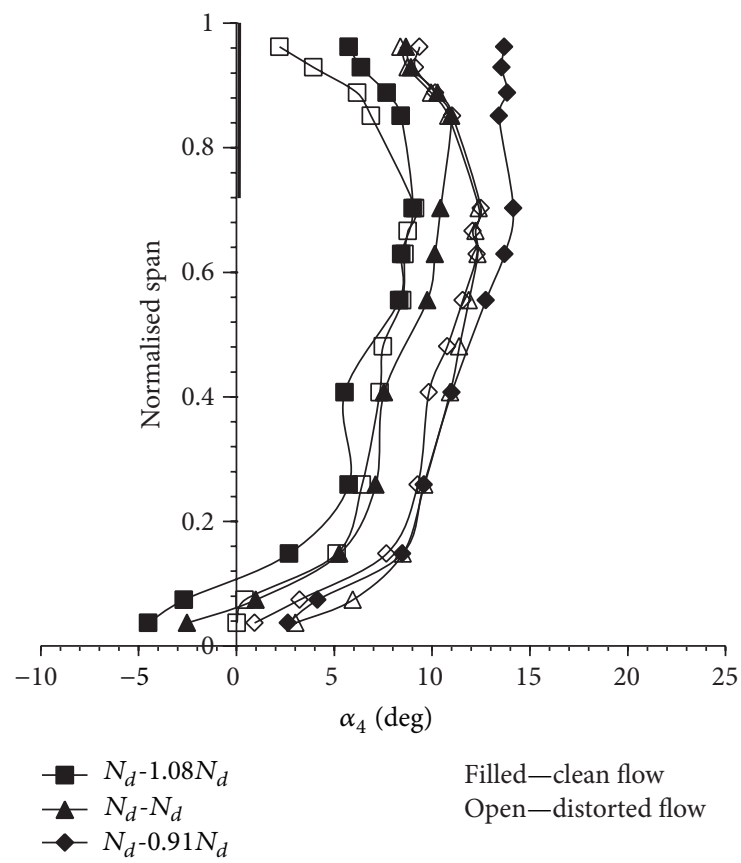

(b) Peak pressure mass flow rate

FIGURE 15: Spanwise variation of flow angle at the exit of rotor-2.

magnitude of axial velocity ratio as expected can be seen as compared to the clean flow situation.

Figure 15 shows the spanwise variation in the flow angle at the exit of rotor-2. The exit flow angle also reflects the effect of radial inflow distortion near the tip region. For higher speed of rotor-2, the flow angle is lower by about 2 to 4 degrees for the design mass flow rate and about 3 to 7 degrees for the peak pressure mass flow rate as compared to other cases near the tip region. For the span between the hub and about $50 \%$ of the blade, the flow angle shows a lower variation in 
its magnitude. A flow angle variation in the range 2 to 4 degrees higher than that of clean flow is observed near the hub region. The performance improvement under the tipstrong inflow distortion can be better appreciated by the flow angle plots (Figures 7(b) and 15(b)). The reduced flow angle towards the tip region indicates an improvement in the blade loading in that region. Since the present contrarotating fan stage is designed for higher aerodynamic loading towards the tip, this leads to better pressure rise under tip-strong inflow distortion. For the hub-strong inflow distortion case, the flow angle distribution shows an increase in its magnitude near the tip region. This indicates a reduction in the loading in that region and hence the pressure rise across the stage compared to the tip-strong inflow distortion.

Figure 16 shows the total pressure coefficient along the span of the blade at the entry of rotor-1, the exit of rotor- 1 , and the exit of rotor- 2 for the design mass flow rate and the design speed combination. The drop in the total pressure coefficient near the tip-strong radially distorted flow region can be seen from the figure. The significant gradient in the total pressure between 70 and $100 \%$ of the span can be observed. The total pressure coefficient remains nearly constant for the remainder of the span at the inlet of rotor-1. The effect of distortion is also observed at the exit of rotor- 1 as explained earlier in Figures 13(a) and 14(a) in the region above 60\% span of the blade. The total pressure coefficient at the exit of rotor2 shows improvement not only in the tip region, but also at other span locations under both clean and tip-strong radially distorted inflow.

Therefore, for the tip-strong radial distortion, the distorted region near the tip region changes the flow parameters in the distorted region at the entry of rotor-1. These flow parameters at the entry to rotor-1 allow the rotor to work under design condition in undistorted region and off design condition in the distorted region. The high aspect ratio of the blade permits this flow disturbance to adjust itself along the span of the blade.

\section{Additional Discussion}

The contrarotating fan stage used in the present study was designed for higher aerodynamic loading of rotor- 1 from $60 \%$ span to the tip of the blade. This permits rotor- 1 to work under near-stall free operation even while rotor- 2 is stalled. The flow behaviour under hub-strong and tip-strong radial distortion can be better understood using the velocity triangles at the hub, mid, and tip section of the contrarotating fan stage at the inlet of rotor-1, exit of rotor-1, and exit of rotor- 2 as shown in Figures 17 and 18.

Figure 17 shows the velocity triangles for the hub-strong radial distortion case at the inlet of rotor-1, exit of rotor-1, and the exit of rotor-2. The solid line represents the clean flow case while the dotted line indicates the distorted inflow condition. It is assumed that the flow enters and leaves the stage axially. The presence of the distortion screen near the hub reduces the axial velocity in that region and for the rest of the span; the flow tends to migrate towards the undistorted flow regime for mass flow continuity. As shown in the figure, near the

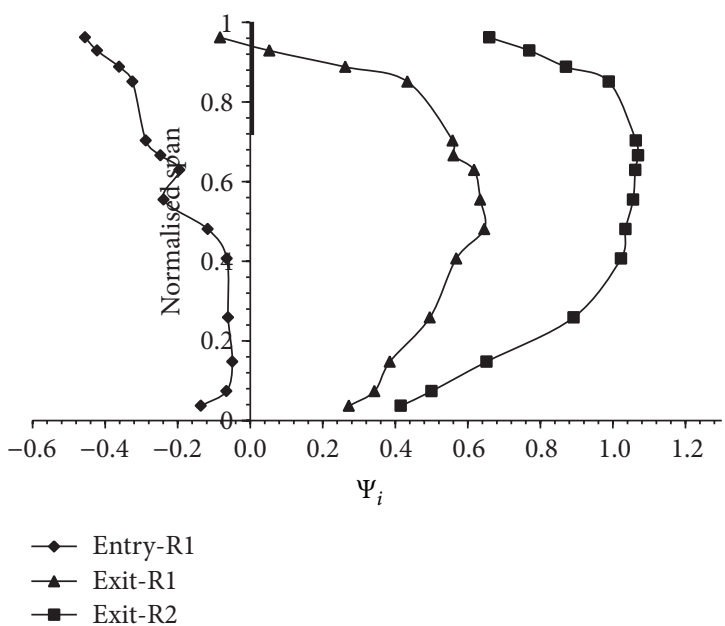

Figure 16: Spanwise total pressure coefficient along the stage at design speed combination.

hub the axial velocity is lower than that of the clean inflow condition. This lower axial velocity increases the blade angle $\beta_{1}$ at the inlet to rotor-1. At the midsection, the axial velocity increases and the blade flow angle is nearly the same as that of the clean flow condition. Near the tip region, the axial velocity improves compared to the clean flow condition, which in turn reduces the blade angle in that region. The change of this blade angle throughout the span at the inlet alters the flow incident to rotor-1 and is higher near the hub. This results in changes in the blade pressure distribution or aerodynamic loading of the blade throughout the span. The presence of the hub-strong radial distortion significantly affects the hub region rather than the tip and, as a result, the performance of rotor-1 deteriorates compared to the clean inflow condition. Assuming the absolute velocity " $C$ " at the exit of rotor- 1 to be the same as the absolute velocity at the entry of rotor-2, the absolute flow angles are consequently the same. The change in the blade angle at the exit of rotor-1 changes the incidence angle at the inlet of rotor-2. As shown in the figure, the flow incident at the entry of rotor- 2 is severely affected near the hub region. The axial velocity distribution at the inlet of rotor2 is found to be different throughout the span. The change of incidence angle at the entry of rotor- 2 changes the blade loading near the hub. This changes the loading along the span and therefore reduces the performance in terms of pressure rise and efficiency of rotor-2. This is also evident from the change in deviation angle at the exit of rotor-2. Under hubstrong radial inflow distortion, the performances of both the rotors change more severely near the hub region with minor reduction near the tip.

Similarly the effect of tip-strong radial inflow distortion can be explained through Figure 18. As shown in the figure, at the inlet of rotor-1, the presence of distortion reduces the axial velocity near the tip region. For the rest of the span, there is an improvement in the axial velocity due to the redistribution on the flow towards the undistorted flow regions. The change in the blade angles near the tip changes the flow incident in that 


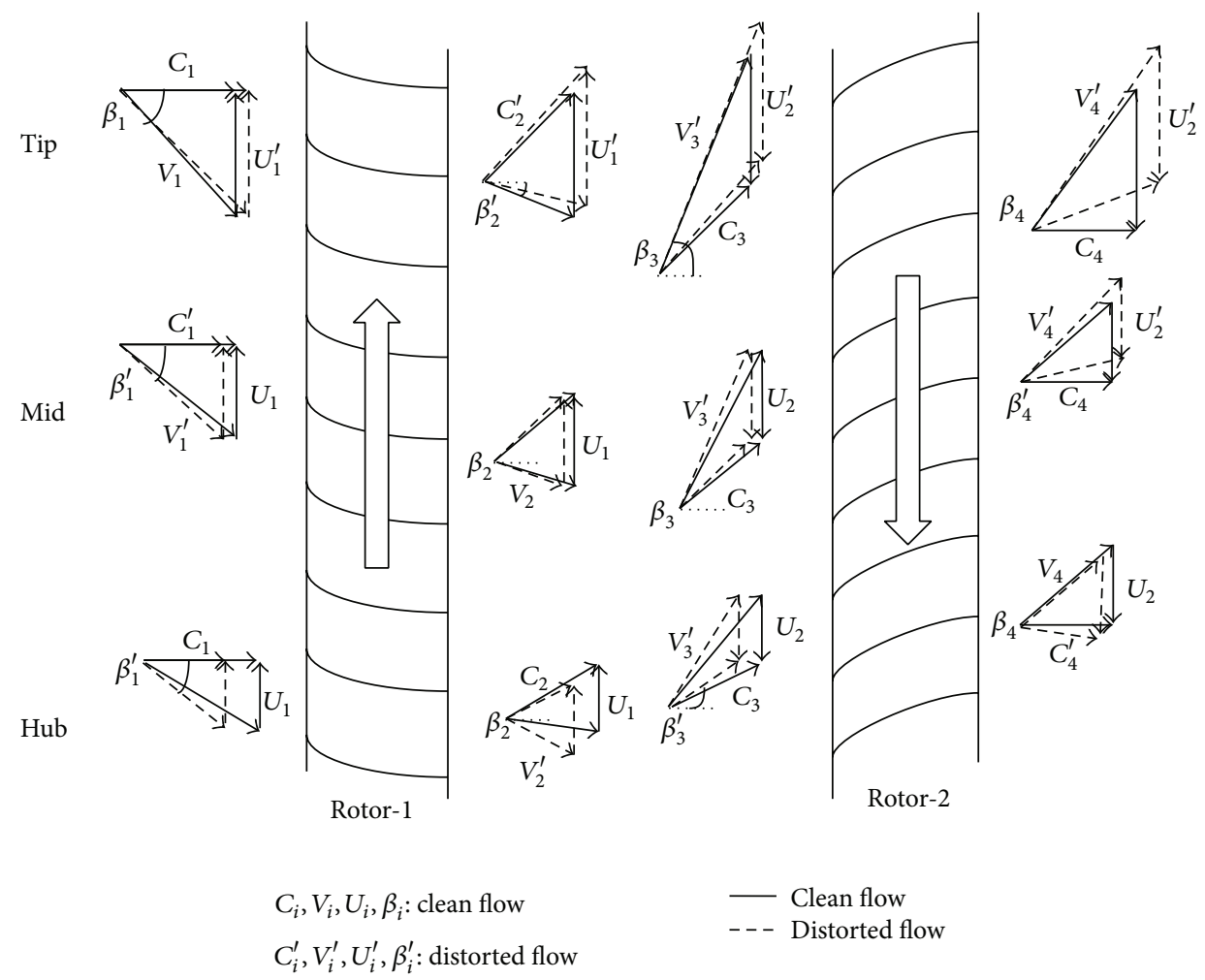

FIGURE 17: Velocity triangles along the span under hub-strong radial distortion operation.

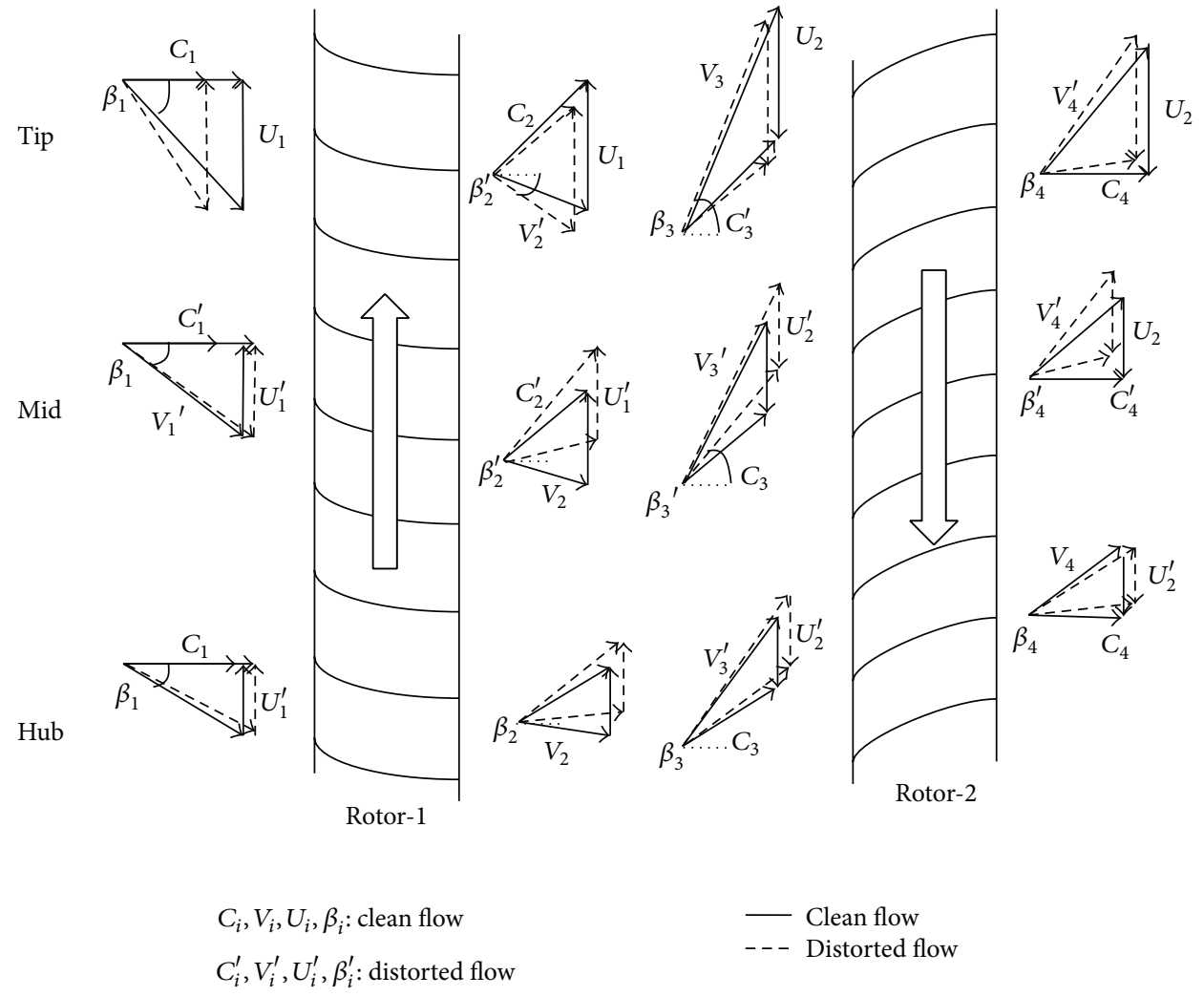

FIGURE 18: Velocity triangles along the span under tip-strong radial distortion operation. 
region. As mentioned earlier, the higher aerodynamic loading of rotor-1 is likely to partly accommodate this change of incidence. The aerodynamic loading in that region therefore does not undergo any major changes; in fact it shows a certain improvement. Near the midsection and the hub region, the change of flow angle has no significant effect as seen for the hub-strong radial inflow distortion. The exit blade angle $\beta_{2}$ is observed to change at the exit of rotor- 1 throughout the span but has no major change near the tip region. The change of this flow angle changes the flow incidence to rotor-2. This leads to a change in the aerodynamic loading of rotor- 2 . The presence of the distortion screen near the tip region improves not only the performance of rotor-1, but also that of rotor-2. The improvements in performance of both the rotors lead to an overall improvement in performance of the stage.

\section{Conclusions}

The present experimental study investigates the effect of both hub-strong and tip-strong radial inflow distortion on the performance of a low speed, high aspect ratio contrarotating axial flow fan stage under different speed combinations of the rotors. The following conclusions related to the performance of the contrarotating fan under these inflow distortions can be summarized as follows.

(1) The overall performance of the stage under hubstrong radial distortion reduces drastically compared to the clean inflow in terms of both pressure rise and operating range. The peak pressure point shifts towards the higher mass flow rate for all the speed combinations and therefore reduces the operating range. The hub covered radial distortion is observed to reduce the overall performance and the operating range by 2 to $4 \%$ under different speed combinations.

(2) For the tip-strong radial distortion, the pressure rise and operating margin show improvement. The performance map shows a shifting of the peak pressure towards the lower mass flow rates with nearly flat operating characteristics for all the mass flow rates. The tip-strong radial distortion improves the operating range by about 6 to $8 \%$ under the different speed combinations studied. However, there is a significant reduction in the efficiency.

(3) The flow incident on rotor-1 along the span of the blade plays a significant role in the overall performance of the contrarotating fan stage.

(4) The high aspect ratio blade permits the flow to migrate from a higher pressure region (undistorted region) towards a low pressure region along rotor1. This migration and hence the redistribution of the flow lead to performance gain or loss depending upon the nature of the inflow distortion. The flow migration also results in changes in the flow parameters in between the rotors and therefore alters the incidence angles for rotor- 2 .

\section{Nomenclature}

$\begin{array}{ll}C: & \text { Absolute velocity, } \mathrm{m} / \mathrm{s} \\ C_{a}: & \text { Axial velocity, } \mathrm{m} / \mathrm{s} \\ C_{p}: & \text { Specific heat, } \mathrm{kJ} / \mathrm{kg} \cdot \mathrm{k} \\ \dot{m}: & \text { Mass flow rate, } \mathrm{kg} / \mathrm{s} \\ \dot{m} \sqrt{T_{0}} / P_{0}: \text { Nondimensional mass flow rate } \\ N: & \text { Speed of the rotor, } \mathrm{rpm} \\ N_{d}: & \text { Design speed of the rotor, } \mathrm{rpm} \\ P_{0}: & \text { Total pressure, } \mathrm{Pa} \\ P_{m}: & \text { Motor power, } \mathrm{kW} \\ T_{0}: & \text { Total temperature, } \mathrm{K} \\ U: & \text { Peripheral speed, } \mathrm{m} / \mathrm{s} \\ V: & \text { Relative velocity, } \mathrm{m} / \mathrm{s} .\end{array}$

\section{Greek Symbols}

$\gamma: \quad$ Ratio of specific heats

$\alpha$ : Absolute flow angle, degrees

$\beta$ : Blade angle, degrees

$\eta_{0}$ : Overall efficiency

$$
=\dot{m} c_{p} T_{01}\left\{\left(P_{03} / P_{01}\right)^{(\gamma-1) / \gamma}-1\right\} /\left(P_{m 1}+P_{m 2}\right)
$$

$\Psi_{0}$ : Total stage pressure rise coefficient

$$
=\left(P_{03}-P_{01}\right) /(1 / 2) \rho C a_{d}^{2}
$$

$\Psi$ : Total pressure coefficient $=\left(P_{0 i}\right) /(1 / 2) \rho U_{\text {tip }, m}^{2}$.

\section{Subscripts}

$\begin{array}{ll}\text { Clean: } & \text { Clean inflow } \\ \text { Distortion: } & \text { Distortion inflow } \\ d: & \text { Design speed } \\ i: & \text { Position of measurement } \\ m: & \text { Mean of tip speeds of rotor-1 and rotor-2 } \\ \text { Peak pressure: } & \text { Peak pressure (partial stall point) } \\ s: & \text { Stage } \\ \text { tip: } & \text { Tip region } \\ 0: & \text { Overall } \\ 1: & \text { Inlet of rotor-1, rotor-1 } \\ 2: & \text { Exit of rotor-1, rotor-2 } \\ 3: & \text { Exit of rotor-2. }\end{array}$

\section{Superscripts}

': Distorted condition.

\section{Conflict of Interests}

The authors declare that there is no conflict of interests regarding the publication of this paper.

\section{Acknowledgment}

This work was partially funded by the Aeronautics Research and Development Board of India which is gratefully acknowledged. 


\section{References}

[1] B. Roy, Harikumar, and A. Batra, "Effect of inlet distortions, co-swirl and counter swirl on single stage axial fan and contra rotating axial fans," in Proceedings of the ISABE, pp. 3-7, Bangalore, India, September 2001, paper no ISABE-2001-1163.

[2] V. I. Mileshin, I. A. Brailko, A. M. Volkov, and V. N. Korznev, "Numerical and experimental investigations of CRF with simulation of flow non-uniformity in the basic flight conditions," in Proceedings of the 27th International Congress of the Aeronautical Sciences, pp. 1-9, Nice, France, September 2010.

[3] D. M. Sandercock and N. L. Sanger, "Some observations of the effects of radial distortions on performance of a transonic rotating blade row," NASA TN D-7842, 1974.

[4] J. E. Moss, "Effect of slotted casing treatment on performance of a multistage compressor," NASA TM X-3350, 1976.

[5] J. F. Schmidt and R. S. Ruggeri, "Performance with and without inlet radial distortion of transonic fan stage designed for reduced loading in the tip region," NASA TP 1294, 1978.

[6] N. L. Sanger, "Effect of rotor meridional velocity ratio on response to inlet radial and circumferential distortion," NASA TP-1278, 1979.

[7] Z. S. Spakovszky, H. J. Weigl, J. D. Paduano, C. M. Van Schalkwyk, K. L. Suder, and M. M. Bright, "Rotating stall control in a high-speed stage with inlet distortion: part I-radial distortion," Journal of Turbomachinery, vol. 121, no. 3, pp. 510516, 1999.

[8] R. V. Chima, "A three-dimensional unsteady CFD model of compressor stability," NASA TM-2006-214117, 2006.

[9] B. Yang and C. G. Gu, "The effects of radially distorted incident flow on performance of axial-flow fans with forward-skewed blades," Journal of Turbomachinery, vol. 135, Article ID 011039, 1 page, 2013.

[10] C. S. Mistry and A. M. Pradeep, "Effect of variation in axial spacing and rotor speed combinations on the performance of a high aspect ratio contra rotating axial fan stage," Proceedings of the Institution of Mechanical Engineers, Part A: Journal of Power and Energy, vol. 227, no. 2, pp. 138-146, 2012.

[11] C. S. Mistry and A. M. Pradeep, "Influence of circumferential inflow distortion on the performance of a low speed, high aspect ratio contra rotating axial fan," Journal of Turbomachinery, vol. 136, Article ID 071009, 11 pages, 2014. 

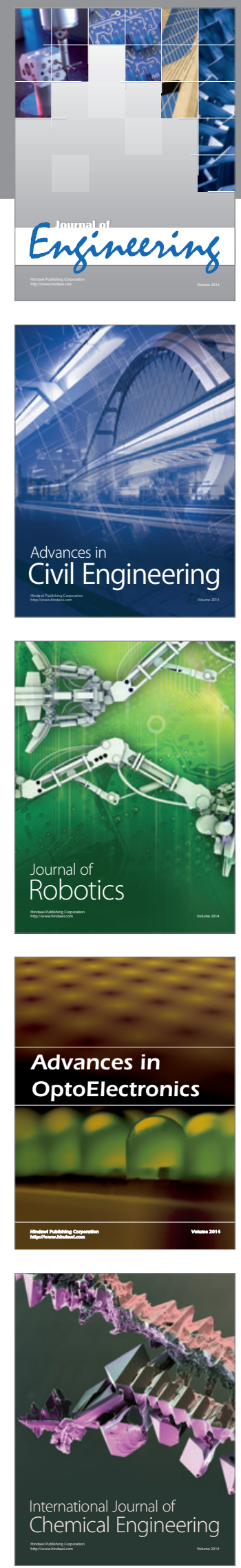

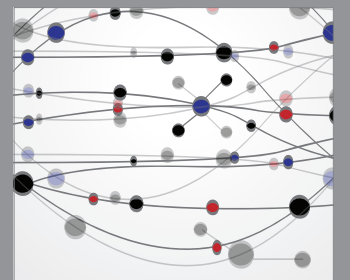

The Scientific World Journal
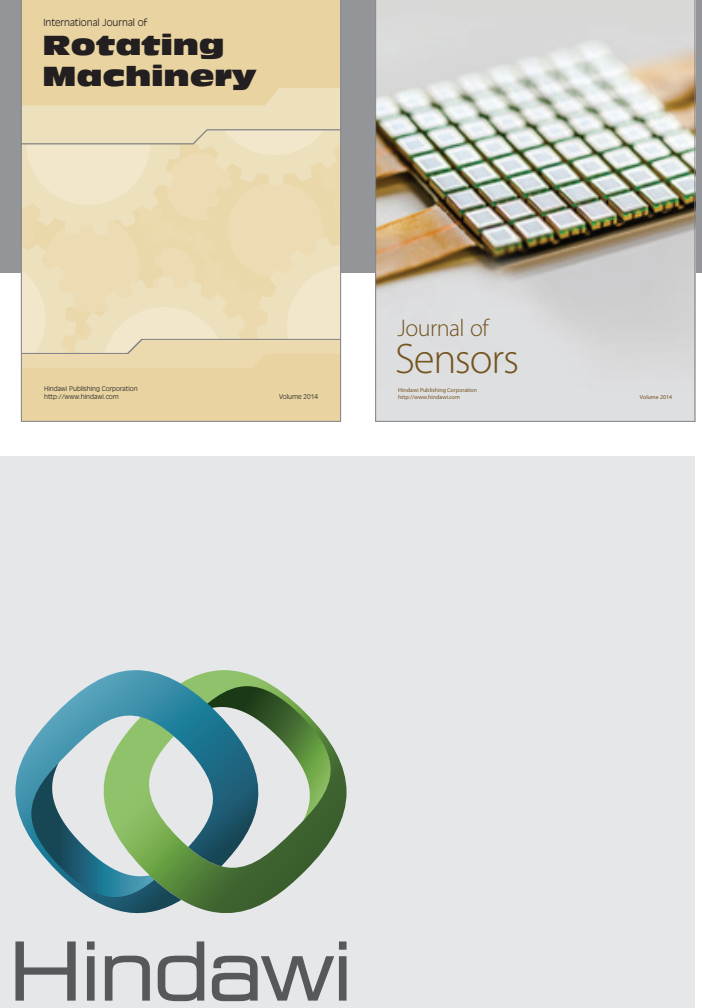

Submit your manuscripts at http://www.hindawi.com
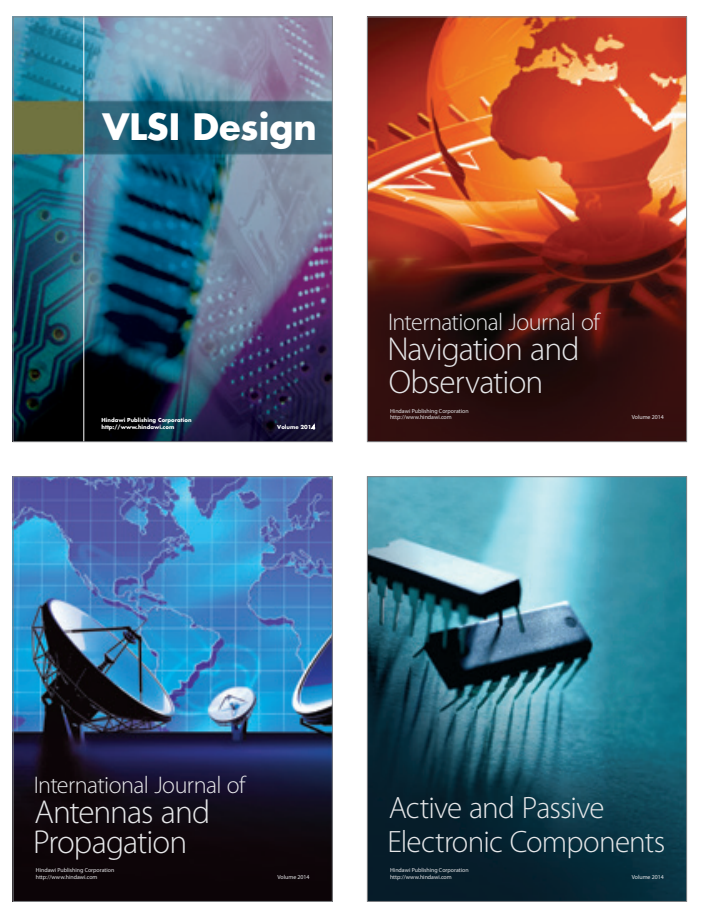
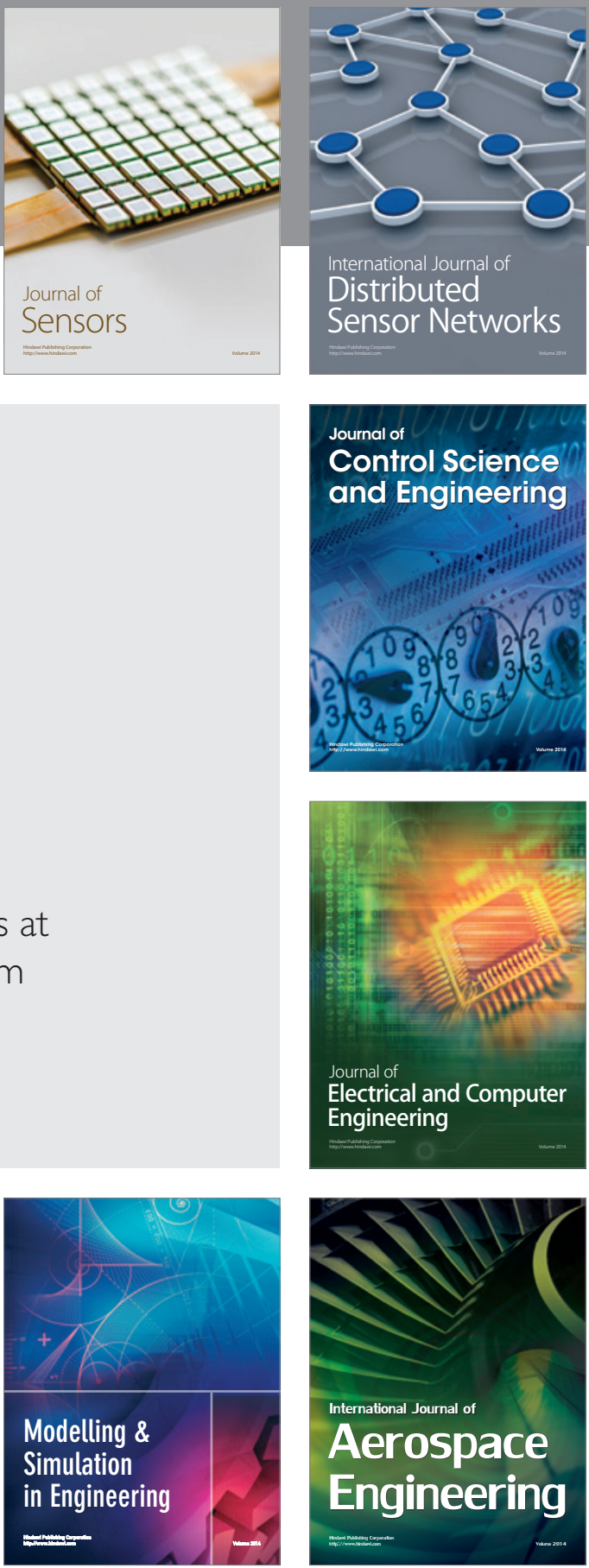

Journal of

Control Science

and Engineering
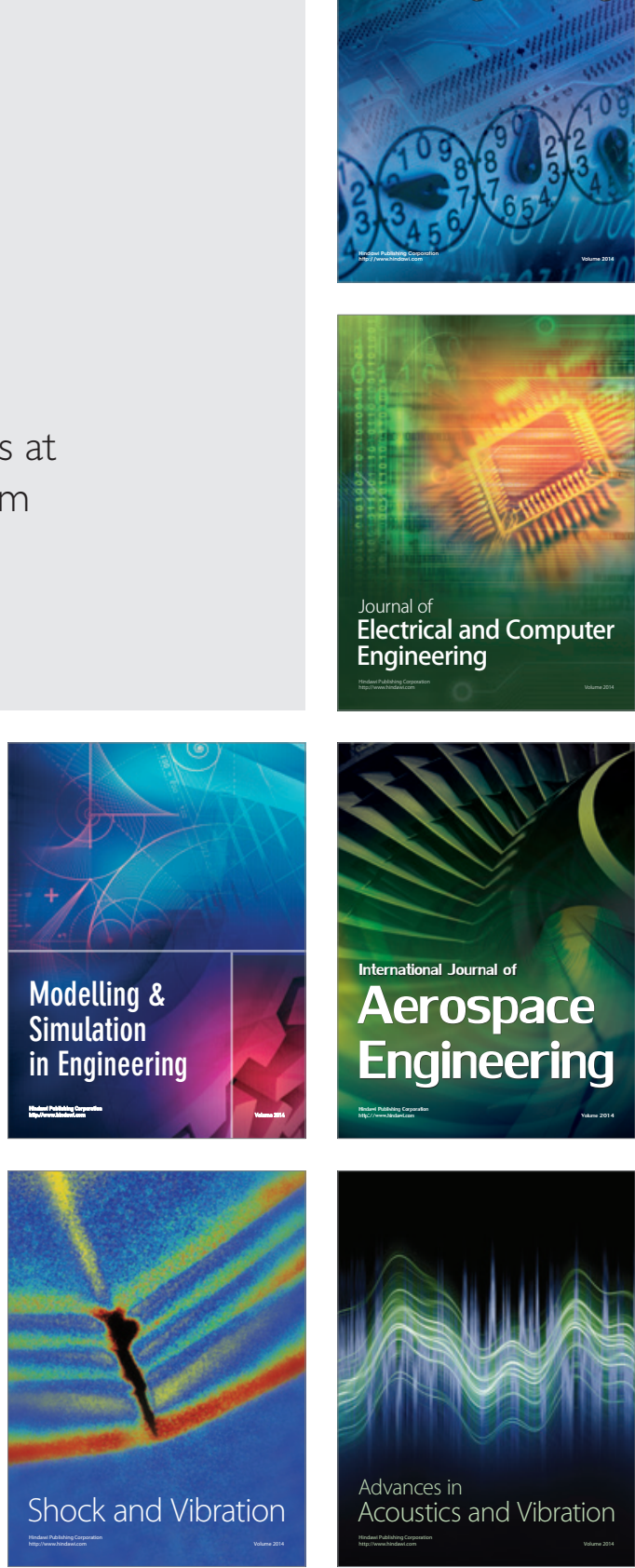